\title{
Evaluation of Manganese Removal rate for MF Pilot Test
}

\author{
Hyungjae Yang ${ }^{1}$, Seounghoon Yi ${ }^{1}$, Yangsuk Song², Younghoon Park ${ }^{2}$, Gyeongrok Son², Yeongju Kang² \\ ${ }^{1}$ Emerging Biz/POSCO ICT \\ 255 Pangyo-ro, Seongnam-city, Gyeonggi-do 13486, Korea \\ hyungyang@hanmail.net; bluesi9@ poscoict.com \\ ${ }^{2}$ Water Quality Research Institute/Gwangju Metropolitan-city \\ 27 Deongnam 1-gil, Nam-gu Gwangju 61748, Korea \\ sogali0728@korea.kr; iamstar@korea.kr; greens24@korea.kr; kyj8995@korea.kr
}

\begin{abstract}
Pilot studies were conducted in Gwangju metropolitan city, Korea to explore the alternatives for manganese removal when MF (micro filter) was used instead of sand filtration in K Waterworks. 94.2 and $92.7 \%$ of the manganese was removed when $0.50 \mathrm{mg} / \mathrm{L}$ for chlorine dioxide was dosed(manganese concentration of raw water was $0.1 \mathrm{mg} / \mathrm{L}$ ) using fifteen minutes reaction time at $\mathrm{pH} 9.0$ and $\mathrm{pH} 7.5$, but $16.8 \%$ and $2.9 \%$ of manganese were removed at $\mathrm{pH} 6.0$ and 3.0, respectively. Manganese removal rate when 0.5 and $1.0 \mathrm{mg} / \mathrm{L}$ for chlorine dioxide was dosed using fifteen minutes reaction time at $\mathrm{pH} 6.9$ without $\mathrm{pH}$ control, $44.0 \%$ and $51.0 \%$ of manganese were removed that are not much different removal rate between at both pHs. And also 42.0 and $51.0 \%$ of manganese were removed using thirty minutes reaction time, 43.0 and $56.0 \%$ of removal rate using forty five minutes reaction time, respectively. It means fifteen minutes of reaction time is enough for chlorine dioxide.
\end{abstract}

Keywords: Microfiltration, Pilot test, Manganese removal, Chlorine dioxide

\section{Introduction}

In some regions including Gwangju metropolitan city of Korean peninsula, manganese is a common element in the soil where it exists primarily as manganese dioxide, which is very insoluble in water. Membrane filtration has become more popular in drinking water treatment recently, since the filtration can control pathogenic microorganisms such as giardia and cryptospiridium very effectively. Also, it has superior treatment capability and performance characteristics in removing suspended solids and colloidal materials, which are the main cause of turbidity and important carrier of metal elements, and it has shown great potential in being an economically substitute to traditional processes ${ }^{1,2}$.

Manganese is reduced from an oxidation state of IV to II and becomes soluble under anaerobic condition ${ }^{3}$. Manganese cannot be removed by membrane filtration without being oxidized to manganese dioxide ${ }^{1.4}$. If manganese can be re-oxidized to an oxidation state of Manganese (IV) oxide is the inorganic compound with the formula $\mathrm{MnO}_{2}$. This blackish or brown solid occurs naturally as the mineral pyrolusite, which is the main ore of manganese and a component of manganese nodules. Manganese is more difficult to oxidize than iron, hence if the treatment process oxidizes and removes manganese; it also oxidizes and removes iron ${ }^{5}$. The principal use for $\mathrm{MnO}_{2}$ is for dry-cell batteries, such as the alkaline battery and the zinccarbon battery ${ }^{6}$-the manganese will become insoluble again. While manganese can be oxidized by chlorine, this reaction may proceed slowly and may not occur until after filtration.

Manganese removal mechanisms in membrane filtration system are oxidation of manganese and removal of the insoluble oxide by sedimentation or filtration, and adsorption to a manganese selective media such as manganese dioxide coated media or ion exchange resin ${ }^{5}$. Manganese can cause staining of clothes and plumbing fixtures, and incrustation of water mains, which can result in black water and debris at the customer's tap ${ }^{5,7}$. The raw water manganese is rarely in excess of the standard for drinking water quality in the waterworks. Manganese removal system using chlorine dioxide is set up in the K waterworks in Gwangju metropolitan city to keep the Ministry of Environment's standard level of $0.05 \mathrm{mg} / \mathrm{L}$. In the United States also, roughly $40 \%$ of public water supplies and one quarter of the municipal wells exceed recommended level of iron and/or manganese ${ }^{8,9}$. Experiments were conducted to evaluate the alternatives for manganese removal when microfiltration was used instead of sand filtration. 


\section{Experiment}

\subsection{Pilot Plant}

Specification of the membrane was $\emptyset 216 \mathrm{~mm}, \mathrm{~L} 1,950 \mathrm{~mm}$, A $60 \mathrm{~m}^{2}, 0.05 \mu \mathrm{m}$ of pore size and pressure hollow fiber type of PVDF material. Finished water qualities were 0.05NTU or less of turbidity, $2.5 \mathrm{log}$ of Giardia and Cryptosporidium. The structure of pilot plant, $120 \mathrm{~m}^{3} / \mathrm{d}$ of treatment capacity of, is shown in Fig. 1. Pilot-scale microfiltration experiments were conducted using chlorine dioxide as oxidant to remove manganese from of the drinking water resource.

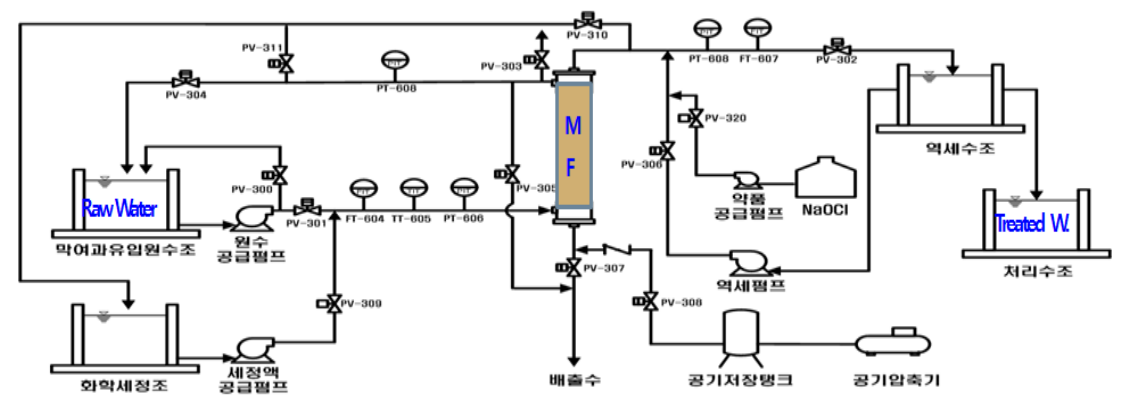

Fig. 1: The Schematic of a pilot-scale MF system.

\subsection{Influent Quality}

Manganese concentrations of raw water was $0.13 \mathrm{mg} / \mathrm{L}$ and maximum was $0.094 \mathrm{mg} / \mathrm{L}$ for 5 years (2010 2014). Average concentrations of year 2010 and 2014 were over $0.05 \mathrm{mg} / \mathrm{L}$ that is the Ministry of Environment's standard level (Table 1). In the case of $4^{\text {th }}$ reservoir for drinking water resources, concentrations of manganese are over $0.05 \mathrm{mg} / \mathrm{L}$ for 15 days a year generally. The UV absorbance was determined using a UV/VIS spectrometer (Cary-3E, USA) and DOC concentration was measured using a DOC analyzer (TOC-V, Shimadzu).

Table 1: Raw Water Quality.

\begin{tabular}{|c|c|c|c|c|}
\hline Parameters & Avg & Max & 2010 & 2014 \\
\hline $\mathrm{pH}$ & 7.8 & 9.3(July 2014) & 8.0 & 7.8 \\
\hline Turbidity(NTU) & 2.85 & 6.67(Oct. 2014) & 2.66 & 3.44 \\
\hline $\mathrm{UV}_{254}\left(\mathrm{~cm}^{-1}\right)$ & 0.048 & $0.095($ Sept. 2012) & 0.049 & 0.045 \\
\hline $\mathrm{MN}(\mathrm{mg} / \mathrm{L})$ & 0.013 & $0.094($ Mar.2011) & 0.014 & 0.008 \\
\hline $\mathrm{DOC}(\mathrm{mg} / \mathrm{L})$ & 1.635 & $2.785($ Dec. 2010) & 2.164 & 1.448 \\
\hline
\end{tabular}

\section{Result and Discussion}

\subsection{Critical Flux}

Critical Flux was evaluated as $49 \mathrm{LMH}\left(\mathrm{L} / \mathrm{min}-\mathrm{m}^{2}\right)$ with influent of raw water through the pilot study from January, 2014 to July, 2015 based on TRM (Trans-membrane Pressure) fluctuation by time variant as $d p / d t$. The method used for the estimation of the flux as shown in Fig. 2 was the nonlinear least squares method from four different equations as $y=-$ $0.050 x+2.375$ at Flux $20 \mathrm{LMH}, \mathrm{y}=0.036 \mathrm{x}+0.567$ at Flux $40 \mathrm{LMH}, \mathrm{y}=0.315 \mathrm{x}-2.644$ at Flux $56 \mathrm{LMH}$ and $\mathrm{y}=0.850 \mathrm{x}-23.745$ at Flux 62 LMH shown in Fig. 2.

\subsection{Manganese Removal with Chlorine dioxide}

Bench-scale jar testing indicated that chlorine dioxide was the most effective oxidant compare with hypochlorite, ozone and permanganate, resulting in adequate removal of the manganese with less than twenty minutes of reaction time reported by Schneider etc. (2001). Hydrogen peroxide, being activated by UV light decomposes into a highly reactive $\mathrm{OH}$ radical with a strong oxidizing potential. Applying this $\mathrm{OH}$ radical, which is termed as advanced oxidize processes (AOPs), can breakdown or change the physical properties of even strong-bonded compounds. However, studied have shown this 
method is not as effective as expected in manganese removal ${ }^{10,11}$. Removal of manganese from surface water has been previously explored that determined in excess of $90 \%$ of dissolved manganese can be removed using pre-oxidation and membrane filtration. The use of oxidation/microfiltration is an effective process for the removal of manganese from surface water ${ }^{5}$. A relatively greater dosage, approximately $3 \mathrm{mg} / \mathrm{L}$ of chlorine $\left(\mathrm{Cl}_{2}\right)$ was required to remove manganese by means of oxidation followed by UF, while substantial iron removal was possible even without chlorine addition ${ }^{12}$, but same dosage as manganese concentration of Chlorine Dioxide when $\mathrm{Mn}^{+2}$ concentration in the influent was $0.1 \mathrm{mg} / \mathrm{L}$, was enough for manganese oxidation at $\mathrm{pH} 7.5$ in the results.

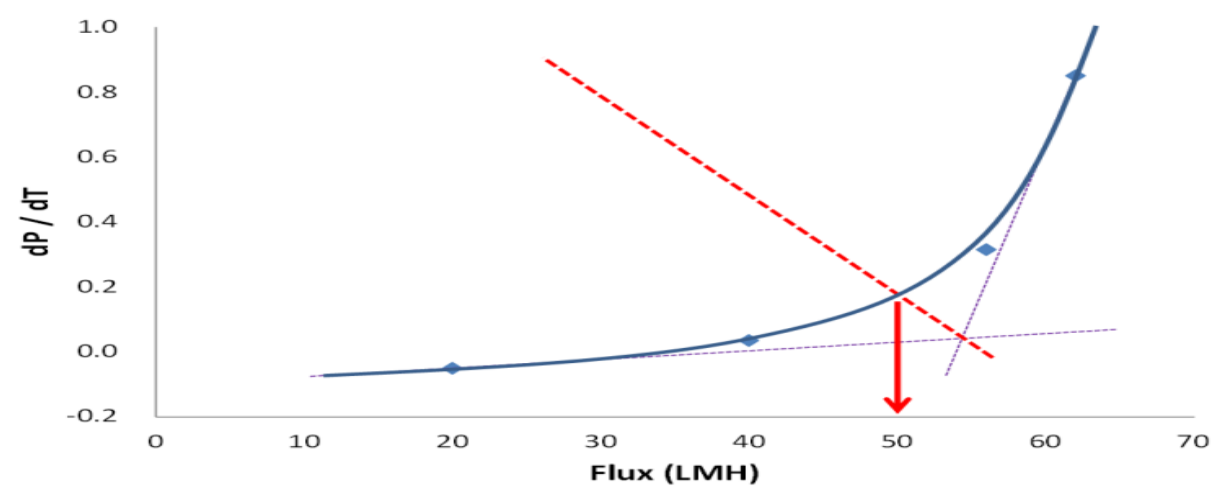

Fig. 2: Critical Flux estimated through the Pilot test.

The kinetic of $\mathrm{Mn}^{+2}$ oxidation using $\mathrm{ClO}_{2}$ was quantified over the following ranges of solution conditions: $\mathrm{pH}=5.5 \sim 9.0$; temp. $=2 \sim 25^{\circ} \mathrm{C}$; DOC $=<0.5 \sim 10 \mathrm{mg} / \mathrm{L}$. Typical oxidant dosages ranged from 105 to $200 \%$ of the stoichiometric amount required for reduced metal ion oxidation ${ }^{13}$. Chlorine dioxide was dosed as oxidant with fifteen minutes of reaction time to remove manganese from the raw water in the experiment. The mean raw water manganese concentration was $0.094 \mathrm{mg} / \mathrm{L}$. The results were that $92.7 \%$ of the manganese was removed when $0.10 \mathrm{mg} / \mathrm{L}$ for chlorine dioxide was dosed in $1.01 \mathrm{mg} / \mathrm{L}$ of manganese using fifteen minutes reaction time and $94.2 \%$ of the manganese was removed at $\mathrm{pH} 9.0$, but $16.8 \%$ and $2.9 \%$ of manganese were removed only at $\mathrm{pH} 6.0$ and 3.0, respectively as shown in Fig. 3.

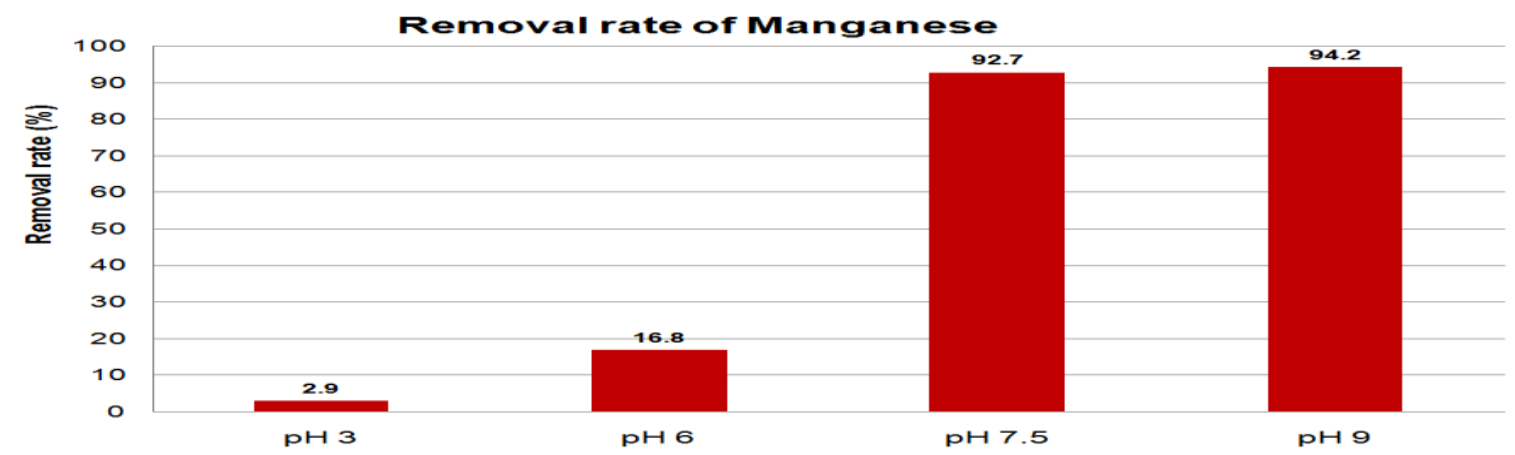

Fig. 3: Removal rate of manganese with chlorine dioxide at $\mathrm{pH} 3.0,6.0,7.5$ and 9.0.

When 0.5 and $1.0 \mathrm{mg} / \mathrm{L}$ for chlorine dioxide was dosed using fifteen minutes reaction time at $\mathrm{pH} 6.9$ without $\mathrm{pH}$ control, $44.0 \%$ and $51.0 \%$ of manganese were removed, and $42.0 \%$ and $51.0 \%$ of manganese were removed, respectively using thirty minutes reaction time, , nothing is different from fifteen minutes reaction time. It means fifteen minutes of reaction time is enough for chlorine dioxide. The manganese concentrations in the filtrate are lower than the feed water concentrations with a $94 \%$ confidence level. But nothing is different removal rate between using fifteen, thirty and forty five minutes reaction time as shown in Fig. 4. Therefore optimal reaction time was estimated as fifteen minutes in the result of experiment. Alkaline $\mathrm{pH}$ condition promoted efficient removal of $\mathrm{Mn}^{2+}$ on the oxide surface. Free chlorine likewise promoted soluble manganese removal on the media surface under both alkaline and acidic $\mathrm{pH}$ conditions. Stronger oxidant as $\mathrm{ClO}_{2}$ resulted in $\mathrm{Mn}^{2+}$ 
oxidation of colloidal $\mathrm{MnOx}(\mathrm{s})$ within the filter ${ }^{13}$. And treated water quality, turbidity of influent and effluent, during winter time are shown in Fig. 4.

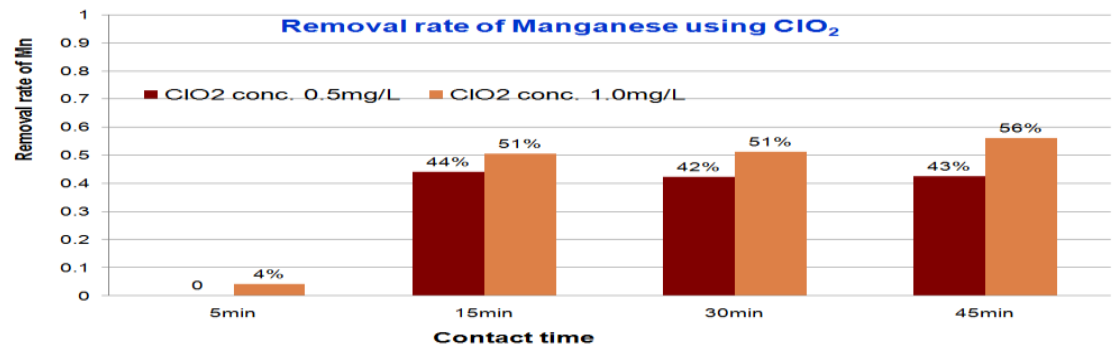

Fig. 4: Removal rate of manganese with chlorine dioxide at $\mathrm{pH} 6.9$.

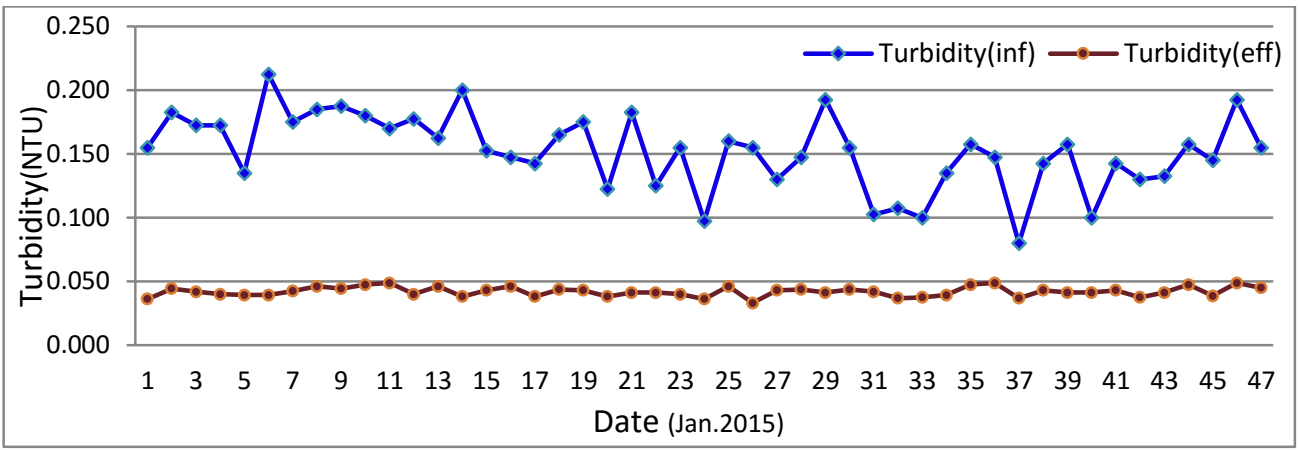

Fig. 5: Turbidity of Influent and effluent during winter time (Jan. 21015).

\section{Conclusion}

Experiment was conducted to evaluate the alternatives for manganese removal using chlorine dioxide when microfiltration was used instead of sand filtration. Critical flux was evaluated as $49 \mathrm{LMH}\left(\mathrm{L} / \mathrm{min} \cdot \mathrm{m}^{2}\right)$ through the pilot test. The method used for the estimation of the flux was the nonlinear least squares method from four different equations at flux $20,40,56$ and $62 \mathrm{LMH}$.

The oxidation of $\mathrm{Mn}(\mathrm{II})$ using $\mathrm{ClO}_{2}$ was rapid, and oxidation rates increased as solution $\mathrm{pH}$ increased. Manganese removal rates were $92.7 \%$ at $\mathrm{pH} 7.5$ and $94.2 \%$ at $\mathrm{pH} 9.0$ when $0.50 \mathrm{mg} / \mathrm{L}$ for chlorine dioxide was dosed using fifteen minutes reaction time, but $16.8 \%$ and $2.9 \%$ of manganese were removed only at $\mathrm{pH} 6.0$ and 3.0, respectively.

When 0.5 and $1.0 \mathrm{mg} / \mathrm{L}$ for chlorine dioxide was dosed using fifteen minutes reaction time at $\mathrm{pH} 6.9$ without $\mathrm{pH}$ control $44.0 \%$ and $51.0 \%$ of manganese were removed, and $42.0 \%$ and $51.0 \%$ of manganese were removed using thirty minutes reaction time. Removal rates in the results are almost same using different reaction time as thirty and forty five minutes. When 0.5 and $1.0 \mathrm{mg} / \mathrm{L}$ for chlorine dioxide was dosed using fifteen minutes reaction time at $\mathrm{pH} 6.9$, manganese removal rates were $44.0 \%$ and $51.0 \%$. And $42.0 \%$ and $51.0 \%$ of manganese were removed using thirty minutes reaction time, nothing is different from fifteen minutes reaction time.

This research was supported by Korea Ministry of Environment as "The Eco-Inovation Project (Global Top Project)" (GT-SWS-11-02-007-7).

\section{References}

[1] Z. Teng, J. Huang, K. Fujita, and S. Takizawa, "Manganese Removal by hollow fiber micro-filter. Membrane separation for drinking water," Desalination, vol. 139, pp. 411-418, 2001.

[2] J. Y. Huang, S. Takizawa, and K. Fujita, Wat. Sci. \& Tech., vol. 41, no. 10-11, pp. 77, 2000.

[3] C. N. Sawyer, P. L. McCarty, and G. F. Parkin, Chemistry for Environmental Engineering, Fourth Ed. New York: McGraw-Hill, pp. 578, 1994.

[4] J. Cho, Membrane Engineering. Korea: Shingkwang Publisher, 2013.

[5] C. Schneider, P. John, and R. Huehmer, "Removal of Manganese by Microfiltration in a Water Treatment Plant," in 
Proceedings of the 2011 Membrane Technology Conference, AWWA\&IWA, March 4-7, 2001, San Antonio, Texas USA.

[6] N. N. Greenwood and A. Earnshaw, Chemistry of the Elements. Oxford: Pergamon Press, pp.1218-20, 1984.

[7] G. C. White, Handbook of Chlorination and Alternate Disinfectants, Fourth Ed. New York: John Wiley and Sons, Inc., 1999.

[8] G. H. Khoe and T. D. Waite, "Manganese and iron related problems in Australian water supplies," Environmental Technology Letters, vol. 10, no. 5, 1989.

[9] US EPA Document, "Membrane Filtration Guidance Manual: Overview and Summary," U.S. EPA Document, EPA No. N/A, 2005.

[10] Z. Teng, J. Y. Huang, K. Fujita, and S. Takizawa, "Manganese removal by hollow fiber micro-filter. Membrane separation for drinking water," Desalination, vol. 139, no. 1-3, pp. 411-418, 2001.

[11] M. A. Rahman, J. Y. Huang, Y. Iwakami, and K. Fujita, Wat. Sci. \& Tech., vol. 41, no. 10-11, pp. 25, 2000.

[12] K. Choo, H. Lee, and S. Choi, "Iron and manganese removal and membrane fouling during MF in conjunction with prechlorination for drinking water treatment," J. of Membrane Science, vol. 267, pp.18-26, 2005.

[13] W. R. Knocke, J. E. Van Benschoten, M. J. Kearney, A. W. Soborski, and D. A. Reckhow, "Kinetics of Manganese and Iron Oxidation by Potassium Permanganate and Chlorine Dioxide," Jour. AWWA, pp.79-86, 1991. 